\title{
SREBP1 promotes the invasion of colorectal cancer accompanied upregulation of MMP7 expression and NF-kB pathway activation
}

Yuyan Gao ${ }^{1,24^{*}} \mathbb{D}$, Xianxiu Nan ${ }^{1}$, Xinjue Shi ${ }^{1}$, Xiaoqin $\mathrm{Mu}^{3 *}$, Binbin Liu ${ }^{3}$, Huifen Zhu ${ }^{3}$, Bingqing Yao ${ }^{3}$, Xinyi Liu ${ }^{3}$, Tianyue Yang ${ }^{3}$, Yiting $\mathrm{Hu}^{3}$ and Shulin $\mathrm{Liu}^{3}$

\begin{abstract}
Background: Sterol-regulatory element binding protein 1 (SREBP1), an intracellular cholesterol sensor located in the endoplasmic reticulum, regulates the intracellular cholesterol by the Insig-Srebp-Scap pathway. Over-expression of SREBP1 can cause dyslipidemia. SREBP1 can regulate the metabolic pathway, and then promote the proliferation of tumor cells. However, there is no relevant research of metastasis and invasion in the field of colorectal cancer (CRC).

Methods: Expression of SREBP1 was manipulated in CRC cell lines with low and high level SREBP1 expression by transfectiong with plasmids containing the SREBP1 gene, or by shRNA. The effect of SREBP1 on cell migration was assayed. The expression of SREBP1, p65 and MMP7 were detected by western blot. Human umbilical vein endothelial cell was used for detection of angiogenesis by adding the culture supernatant from HT29 and SW620. The level of reactive oxygen species (ROS) was detected by Dihydroethidium (DHE) staining. NF-KB inhibitor SN50 was used to test the relationship of SREBP1, NF-KB pathway and MMP7.

Results: We found that the expression of SREBP1 in colon adenocarcinoma was significantly higher than that in noncancerous tissues, especially in the invasive tumor front including tumor budding. In vitro, SREBP1 over-expressed in colon cancer cell lines HT29 promoted angiogenesis in endothelial cells, increased ROS levels, phosphorylation of NF-KB-p65 and increases MMP7 expression. The effect of SREBP1 on expression of MMP7 was lost following treatment with the NF-KB inhibitor SN50.
\end{abstract}

Conclusion: Our results suggest that SREBP1 can promote the invasion and metastasis of CRC cells by means of promoting the expression of MMP7 related to phosphorylation of p65.

Keywords: CRC, Invasion, MMP7, NF-KB, SREBP1

\section{Background}

Colorectal cancer is one of the most common malignancies. The recurrence and metastasis of colorectal cancer are the main risk factors affecting the prognosis $[1,2]$. A high-fat diet and dyslipidemia are risk factors for colorectal cancer [3]. Sterol-regulatory element binding proteins (SREBPs) are a cholesterol sensor located in the endoplasmic reticulum that regulate intracellular cholesterol via the Insig-Srebp-Scap pathway [4, 5]. In response

\footnotetext{
*Correspondence: 33639877@qq.com; muxiaoqin@ems.hrbmu.edu.cn 'The Department of Radiotherapy, Beijing Luhe Hospital, Capital Medical University, Beijing, China

${ }^{3}$ Systemomics Center, College of Pharmacy, and Genomics Research Center, Harbin Medical University, Harbin, China

Full list of author information is available at the end of the article
}

to insulin signaling, SREBP1 is transported from the endoplasmic reticulum to the Golgi in a coat protein complex II(COPII)-dependent manner, processed by proteases in the Golgi, once SREBP1 is activated, the mature (sheared) protein translocates to the nucleus to induce lipid-producing gene expression [6]. Lipid metabolism has an important relationship with tumorigenesis and development, where abnormal lipid metabolism promotes growth in many tumor types [7, 8]. For example, SREBPs can regulate the increase of 3-hydroxy-3-methylglutaryl CoA (HMG-CoA) reductase and increase the absorption of cholesterol in prostate cancer, while the HMG-CoA reductase inhibitor lovastatin can induce apoptosis in a variety of tumor cells [9].

(c) The Author(s). 2019 Open Access This article is distributed under the terms of the Creative Commons Attribution 4.0 International License (http://creativecommons.org/licenses/by/4.0/), which permits unrestricted use, distribution, and reproduction in any medium, provided you give appropriate credit to the original author(s) and the source, provide a link to the Creative Commons license, and indicate if changes were made. The Creative Commons Public Domain Dedication waiver (http://creativecommons.org/publicdomain/zero/1.0/) applies to the data made available in this article, unless otherwise stated. 
Through a genetic analysis, our group previously found that metabolic dysregulation (include lipid metabolism) is key to promoting BALB/c mice accelerated colorectal carcinogenesis following dextran sulfate sodium salt (DSS)induced colitis [10]. In fact, most tumor cells endogenously synthesize $95 \%$ of fatty acids, while normal cells mainly ingest from the outside [11]. Furthermore, a series of studies suggest that lipid metabolism plays an important role in tumor proliferation [12-14]. However, there is little research on the role of SREBP1 in tumor invasion and metastasis.

In order to clarify the role of SREBPs in colon cancer, we examined the expression of SREBP1 in clinical samples. In addition, we manipulated expression of SREBPs in colon cancer cell lines, and found that SREBP1 expression is associated with invasion, metastasis and angiogenesis; Finally, we demonstrated that SREBP1 induced MMP7 expression via the NF-kB pathway.

\section{Methods}

\section{Reagents, tissues and patients}

Formalin-fixed, paraffin-embedded specimens, including primary carcinoma specimens $(n=60)$ and corresponding non-tumor normal tissues specimens used for $\mathrm{IHC}$ were collected from colorectal cancer patients who underwent surgery from 2008 to 2010. All cases were confirmed as colorectal cancer by a pathologist. Primary carcinomas were assessed according to the seventh edition of the American Joint Committee on Cancer (AJCC) staging system. All CRC patients' data and tissue samples were collected from the Affliated Tumor Hospital of Harbin Medical University. No patients had received preoperative radiotherapy or chemotherapy at time of tissue collection. The study was approved by the Ethics Committee of the Affliated Tumor Hospital of Harbin Medical University, Harbin, China (Table 1).

\section{Evaluation of SREBP1 immunohistochemical results}

SREBP1 expression was assayed using standard immunohistochemistry techniques. SREBP1 antibody (ab191857, Abcam, USA) concentration was 1:300. IHC staining sections were observed by brightfield microscopy. Ten high power visual fields were selected for each section, and 100 tumor cells were observed in each visual field. The average positive cell proportion was calculated. The positive criteria was brown-yellow granules in nucleus or cytoplasm. The positive $(+)$ criteria was positive cells $>10 \%$, the negative $(-)$ criteria was positive cells $<10 \%$ or no positive cells.

\section{Antibodies}

Antibodies against MMP7, MMP8, and MMP9, were purchased from Proteintech (Wuhan, China); NF-kB p65, and NF-kB p-p65 from Cell Signaling Technology; SREBP1,
Table 1 Clinicopathologic characteristics of colorectal cancer patients

\begin{tabular}{|c|c|c|}
\hline \multirow{2}{*}{\multicolumn{2}{|c|}{$\begin{array}{l}\text { Characteristics } \\
\text { Age(years) }\end{array}$}} & \multirow[t]{2}{*}{$n=60(\%)$} \\
\hline & & \\
\hline$\leq 60$ & & $32(53.3)$ \\
\hline$>60$ & & $28(46.7)$ \\
\hline \multicolumn{3}{|l|}{ Gender } \\
\hline male & & $27(45)$ \\
\hline female & & $33(55)$ \\
\hline \multicolumn{3}{|l|}{ Stage } \\
\hline \multirow[t]{2}{*}{ T } & T3 & $52(86.7)$ \\
\hline & T4a & $8(13.3)$ \\
\hline \multirow[t]{3}{*}{ N } & NO & $27(45.0)$ \\
\hline & $\mathrm{N} 1$ & $26(43.3)$ \\
\hline & N2 & $7(11.7)$ \\
\hline \multicolumn{3}{|l|}{ Differentiation } \\
\hline Well & & $3(5)$ \\
\hline Moderate & & $37(61.7)$ \\
\hline Poor & & 20(33.3) \\
\hline
\end{tabular}

from Abcam (Cambridge, MA, USA); and $\beta$-actin mouse $\mathrm{mAb}$ was purchased from Genscript (Jiangsu, China).

\section{Cell culture}

Human colorectal cancer cell lines (HT29, SW620 cell lines) and human umbilical vein endothelial cells (HUVEC) were purchased from the American Type Culture Collection, and grown in RPMI or L15 medium (as indicated by the supplier) supplemented with $10 \%$ fetal bovine serum in $37^{\circ} \mathrm{C}$ incubator with a humidified, 5\% CO2 atmosphere. The cell lines (HT29, SW620) had been identified by professional STR profiling and tested negative for mycoplasma contamination.

\section{Lentiviral vector construction}

The SRRBP1 sequence was synthesized by Shanghai GenePharma Co and cloned into pLVX vector. Four short hairpin RNAs (shRNAs) target sequence for SREBP1 gene were synthesized by Shanghai GenePharma Co, Ltd., to deplete the expression of SREBP1 in colon cancer cells. A scrambled shRNA was used as a negative control. shRNA oligos were cloned into the pLKO vector. Then combinant lentivirus was generated by co-transfecting shRNA plasmids or over-expression plasmids and pHelper plasmids into HEK293T cells using Lipofectamine 2000 (Invitrogen) according to the manufacturer's instruction.

\section{Transfection}

Viral titer of shRNA plasmids or over-expression plasmids was $2^{*} 10^{\wedge} 9 \mathrm{ifu} / \mathrm{ml}$, as determined by ELISA. For cell transfection, SW620 cells and HT29 cells were 
seeded in six-well plates and transfected with the constructed lentivirus containing at a multiplicity of infection. Final concentration polybrene was $4 \mu \mathrm{g} / \mathrm{ml}$. Viruses were $0.5,1,2,4 \mathrm{ul}$ respectively, and $1 \mathrm{ul}$ viruses was best. Puromycin $(2 \mu \mathrm{g} / \mathrm{ml})$ was added $24 \mathrm{~h}$ after infection, then stable transfected cell lines were screened. The knockdown or over-expression efficiency was determined by protein levels at $48 \mathrm{~h}$ after transfection.

\section{Reactive oxygen species (ROS) staining}

The Dihydroethidium staining was used to detect ROS. Cells were plated in 24-well plates for more than $12 \mathrm{~h}$, then fixed with formaldehyde for $30 \mathrm{~min}$, and $30 \mu \mathrm{M}$ Dihydroethidium (Invitrogen) staining the cells at room temperature for $5 \mathrm{~min}$, at last checked by Immunofluorescence assay.

\section{Cell migration experiment}

Cells were plated in 24-well plates, 1640 medium with $1 \%$ serum in the upper chamber and 1640 medium with $10 \%$ serum in the lower chamber. HT29 cell were cultured for $48 \mathrm{~h}$ and SW620 cell were cultured for $72 \mathrm{~h}$. Washed twice with PBS, then fixed with methanol for $30 \mathrm{~min}$, stained with $0.1 \%$ crystal violet for $20 \mathrm{~min}$, and washed twice with PBS again. Gently wipe off the cells at the bottom of the upper chamber, peel off the membrane and mount on a glass slide sealed with a neutral gum. 10 microscopic fields of cells were observed and counted.

\section{Angiogenesis experiment}

After the tumor cells were cultured with serum-free medium for $24 \mathrm{~h}$, the supernatant was collected by centrifugation at $1000 \mathrm{rpm} / \mathrm{min}$ for $10 \mathrm{~min}$ to remove the cell mass, and then centrifuged at $12000 \mathrm{rpm} / \mathrm{min}$ for 10 min to further remove cell debris. The resulting supernatant is tumor cell conditioned culture supernatant (TCM). The density of human umbilical vein endothelial cells (HUEVC) was adjusted to $1 \times 10^{5}$ with TCM. Took 200ul Matrigel (BD) into a 24-well plate and incubate at $37^{\circ} \mathrm{C}$ for $2 \mathrm{~h}$. Took $1 \mathrm{ml}$ HUEVC that had adjusted density to glue. After culturing the cells for $8 \mathrm{~h}$, observe the formation of blood vessel and photograph. Angiogenic capacity is determined by the number of branch nodes formed by human umbilical vein endothelial cells.

\section{Immunoblot assay}

In brief, cells were collected by using a scraper and washed once with cold PBS. The cells were then lysed in lysis buffer $(50 \mathrm{mM}$ Tris- $\mathrm{HCl}, 250 \mathrm{mM} \mathrm{NaCl}, 5 \mathrm{mM}$ EDTA, $50 \mathrm{mM} \mathrm{NaF}, 0.1 \% \mathrm{NP}-40)$ supplemented with $1 \%$ protease inhibitor cocktail. Equal amounts of proteins

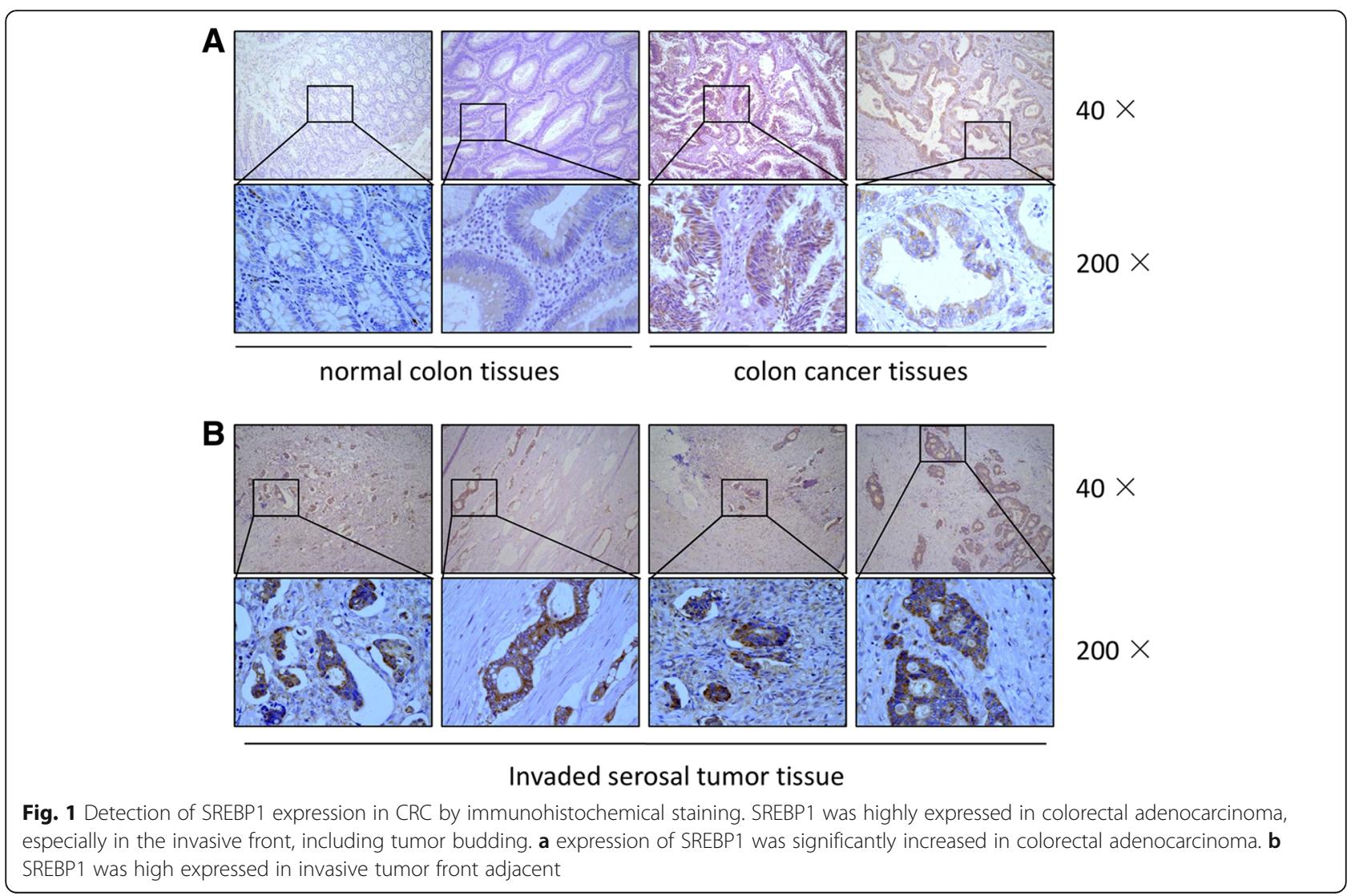


were size-fractionated by $7.5-15 \%$ SDS-PAGE, and then transferred to polyvinyl difluoride (PVDF) membranes. Primary antibodies were incubated overnight. The secondary antibody was incubated $1 \mathrm{~h}$, which was either anti-mouse IgG or anti-rabbit IgG. The Western blot was repeated at least three times.

\section{Statistical analysis}

Three independent experiments were performed prior to statistical analysis. The data was represented as mean \pm S.D. $P<0.05$ was considered statistically significant by unpaired Student's $t$-test.

\section{Results}

SREBP1 is highly expressed in colorectal adenocarcinoma, especially in the invasive tumor front, including tumor budding

Paraffin embedded tumor tissue and corresponding paracancerous tissue were collected from 60 patients with colorectal cancer and stained by immunohistochemistry (IHC) for SREBP1. The IHC staining showed that the expression of SREBP1 was significantly increased in colorectal adenocarcinoma, especially in the invasive tumor nests front adjacent to intestinal adipose tissue, as compared to normal colorectal tissues (Fig. 1). This pattern of expression suggests that SREBP1 expression may be related to tumor invasion and metastasis.

SREBP1 promotes the invasion of colon cancer cells and increases the angiogenic capacity of endothelial cells

To demonstrate the role of SREBP1 in the metastasis of colorectal cancer cells, we over-expressed SREBP1 in the HT29+ cell line and stably knocked down SREBP1 in the SW620 cell line. In a transwell cell invasion assay, tumor cells with SREBP1 expression (HT29 SREBP1 ${ }^{\text {oe }}$, $44.83 \pm 1.58$, and SW620, $31.67 \pm 0.88$ ) were significantly more invasive than those cells that express lower levels of SREBP1 (HT29, $18.33 \pm 0.88$, and SW620 SREBP1 ${ }^{\mathrm{kd}}$, $9.83 \pm 0.95$ ) (both $P<0.001$ ) (Fig. $2 \mathrm{a}, \mathrm{b}, \mathrm{c}$ ). In angiogenesis experiments, we co-cultured HUVEC cells with the HT29+ SREBP1 ${ }^{\text {oe }}$ cells, SW620 SREBP1 ${ }^{\text {kd }}$ cells or the parental cell lines for $48 \mathrm{~h}$; The results showed increased

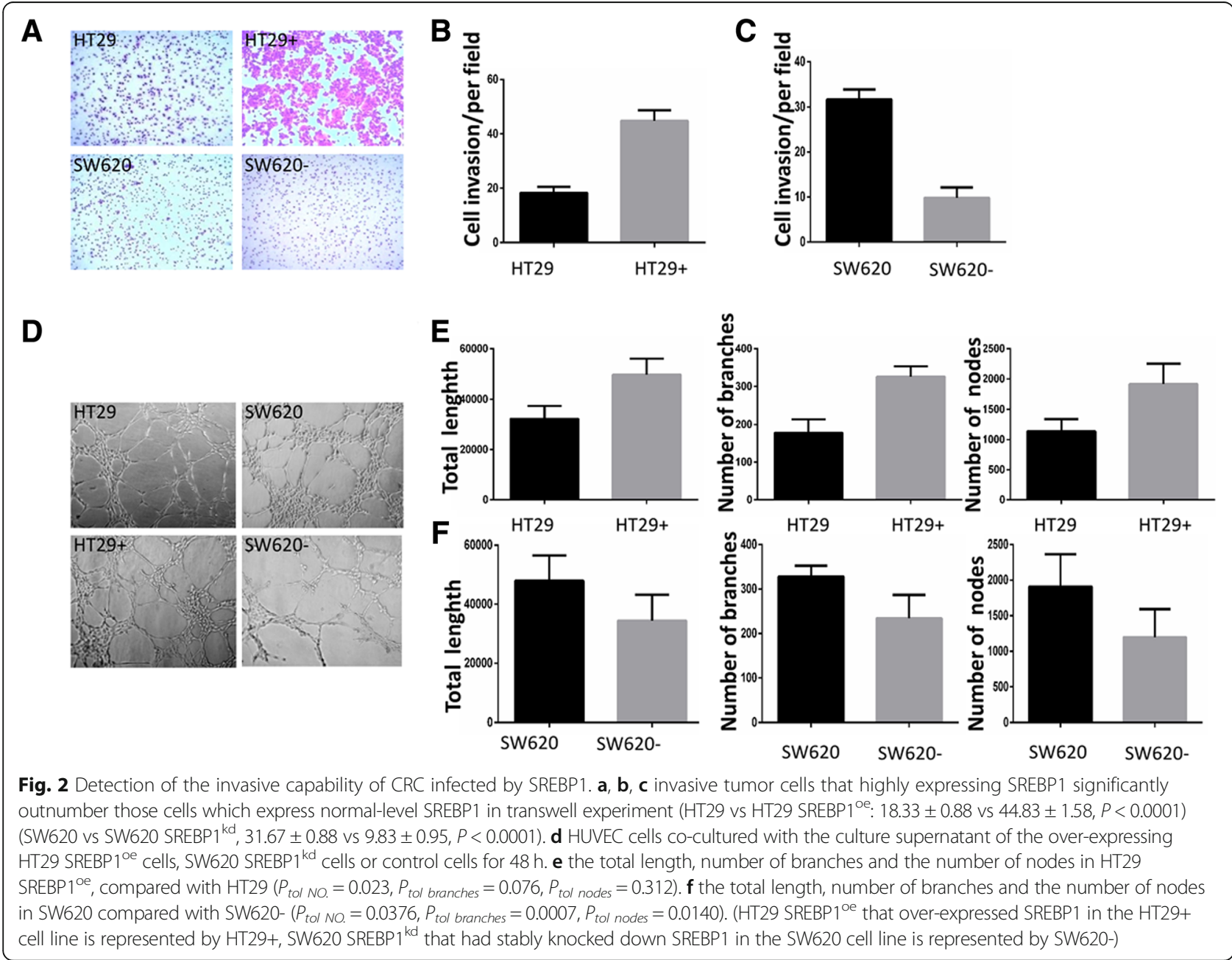


numbers of nodes and area of blood vessels formed by HUVEC cells co-cultured with the HT29+ SREBP $1^{\text {oe }}$ cells than with media from the parental HT29+ cells $\left(P_{\text {tol NO. }}=0.023, P_{\text {tol branches }}=0.076, P_{\text {tol nodes }}=0.312\right)$. Conversely, HUVEC cells cultured with SW620 SREBP $1^{\mathrm{kd}}$ had less branches, nodes and area of blood vessels than cultured with conditioned media from SW620 parental cells $\left(P_{t o l ~ N O}=0.0376, P_{\text {tol branches }}=\right.$ $0.0007, P_{\text {tol nodes }}=0.0140$ ) (Fig. $2 \mathrm{~d}, \mathrm{e}, \mathrm{f}$ ). The cell invasion and angiogenesis data indicate that SREBP1 both increases tumor invasiveness and enhances HUVEC cell angiogenesis both of which play an important role in the development and metastasis of CRC and other tumors.

\section{SREBP1 can elevate the level of ROS in colorectal cancer cells}

As increased ROS can promote invasion of cells by activation of the NF- $\mathrm{kB}$ pathway [15], we hypothesized that SREBP1 might enhance the invasion and tumor angiogenesis through the enhancement of ROS. To test this hypothesis, we compared the levels of ROS by immunofluorescence between the HT29+ SREBP $1^{\text {oe }}$ and SW620 SREBP $1^{\mathrm{kd}}$ cells and the parental cells. As hypothesized, we observed higher levels of ROS in HT29+ SREBP $1^{\text {oe }}$ as compared to HT29, and in SW620 as compared to SW620 SREBP1 ${ }^{\text {kd }}$ (Fig. 3). These results suggest that CRC cell lines with higher SREBP1 expression have higher levels of ROS.

\section{SREBP1 promotes the expression of MMP7}

As ROS can modulate the expression of MMP7 [16], we examined the expression of SREBP1, MMP7, MMP8 and MMP9 in our cell lines. In SREBP1 over expressing HT29 cells, expression of MMP7 was increased by Western blot analysis, while the expression of MMP7 decreased after SREBP1 knockdown in SW620 cells. SREBP1 over expression is positively correlated with the expression of MMP7, with MMP7 expression significantly increased in SREBP1 ${ }^{\text {oe }}$ cells, and decreased in SW620 SREBP1 ${ }^{\mathrm{kd}}$ cells as compared to the parental cell lines (Fig. 4a, b). The expression of MMP8 and MMP9, however, were not markedly changed following modulation of SREBP1 (Additional file 1), suggesting that MMP8 and MMP9 expression is not regulated by SREBP1 in colon cancer cells.

SREBP1 activates phosphorylation of NF-KB protein p65 In order to determine the mechanism which by SREBP1 regulates MMP7, we examined activation of the MMP7

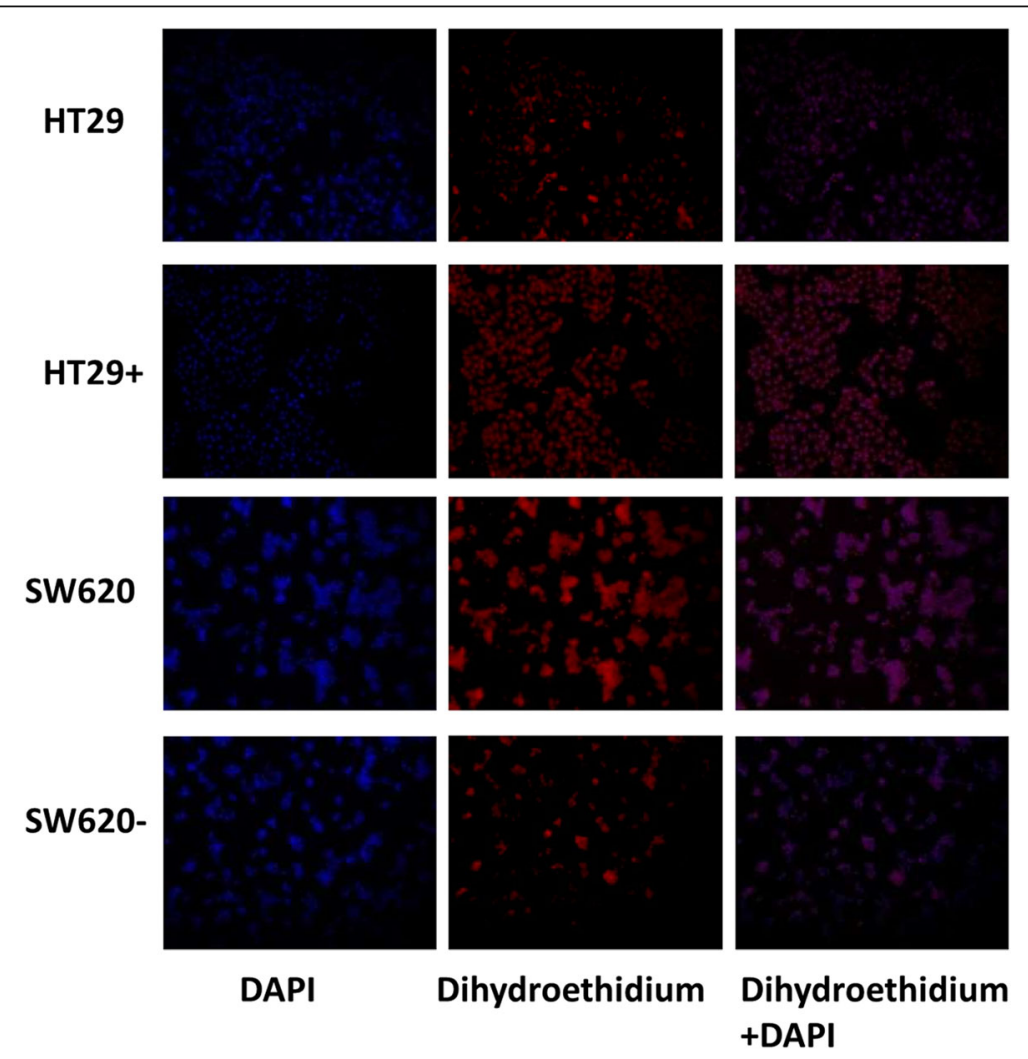

Fig. 3 Detection of the ROS levels. Levels of ROS in HT29 SREBP1 ${ }^{\text {oe }}$, and SW620 SREBP ${ }^{\mathrm{kd}}$ cells along with that of control cells was examined with dihydroethidium. (HT29 SREBP1 ${ }^{\text {oe }}$ that over-expressed SREBP1 in the HT29 cell line is represented by HT29+, SW620 SREBP1 ${ }^{\text {kd }}$ that had stably knocked down SREBP1 in the SW620 cell line is represented by SW620-) 
A

MMP7

SREBP1

B-ACTIN

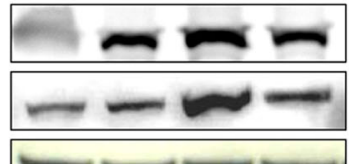

HT29 HT29+ SW620 SW620-

C $_{\text {pP-65 }}$

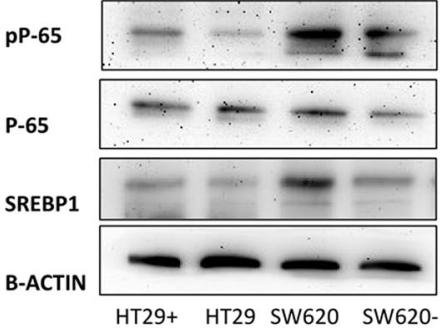

E

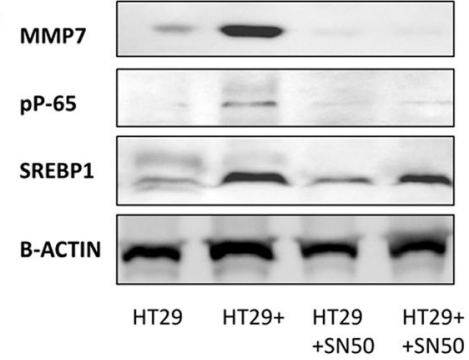

B

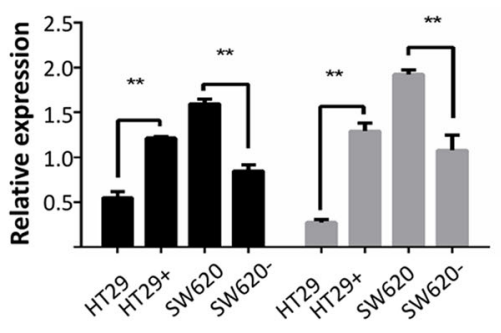

D

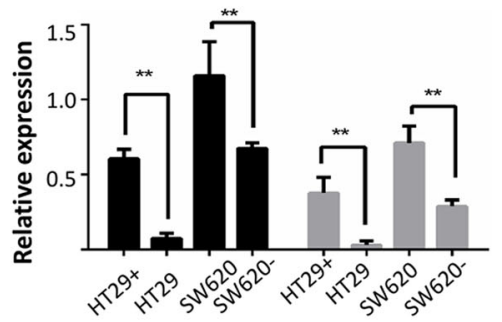

F

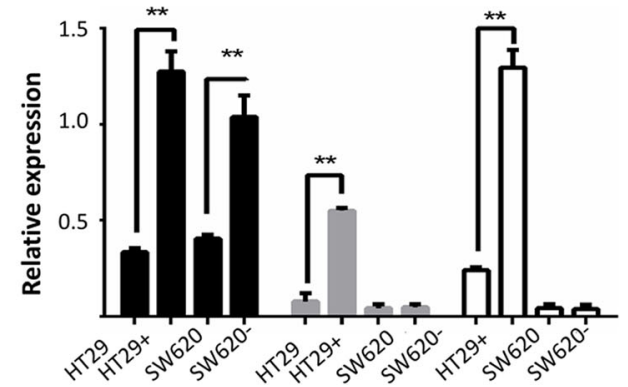

Fig. 4 The role of p65 phosphorylation in MMP7 and SREBP1 increased concomitantly. SREBP1 promotes the expression of MMP7 and activates phosphorylation of NF-KB protein p65. $\mathbf{a}$, $\mathbf{b}$ the relationship between SREBP1 and MMP7 tested by western bolt. $\mathbf{c}$, $\mathbf{d}$ the relationship between

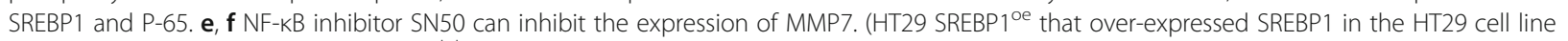
is represented by HT29+, SW620 SREBP $1^{\text {kd }}$ that had stably knocked down SREBP1 in the SW620 cell line is represented by SW620-)

related NF- $\mathrm{KB}$ pathway in the $\mathrm{HT} 29+\mathrm{SREBP}^{\mathrm{oe}}$ and SW620 SREBP1 ${ }^{\mathrm{kd}}$ cell lines. Western blot analysis showed that phosphorylation of NF-kB p65 subunit was enhanced with over expression of SREBP1 (Fig. 4c, d). To explore the functional relationship between NF- $\mathrm{kB}, \mathrm{SREBP} 1$ and MMP7, we treated the SREBP1 over-expressing cells and the control group with SN50, an inhibitor of NF-kB, to block the NF- $\mathrm{kB}$ pathway. Consistent with our hypothesis that SREBP1 promotes MMP7 expression via the NF- $\mathrm{BB}$ pathway, expression of MMP7 was down regulated following SN50 treatment (Fig. 4e, f). Our data suggest that SREBP1 promotes the expression of MMP7 by activating the phosphorylation of $\mathrm{p} 65$ and thus the NF- $\mathrm{kB}$ pathway, leading to an increase in the invasive capacity of intestinal cancer cells.

\section{Discussion}

In the present study, we found that SREBP1, a cholesterol sensor, is over-expressed in colorectal tumor tissues, especially in invasive tumor front including tumor budding compared with normal tissue, suggesting that SREBP1 is associated with invasion and metastasis of colorectal cancer. In subsequent in vitro experiments, we demonstrated that co-culture with cell culture supernatant of high expressing SREBP1 colorectal cancer cells in vitro can promote HUVEC cell angiogenesis. We also show that colorectal cancer cells with higher SREBP1 are more invasive, and express higher levels of MMP7, the expression of which is regulated via ROS and the NF- $\kappa$ B pathway.

SREBP1, a well-recognized cholesterol regulator, is an important transcriptional protein that regulates lipid synthesis [17] with a well-studied function in lipid metabolism [18]. A previous study showed down-regulating TIP30 activated the Akt/mTOR signaling pathway to up-regulate SREBP1 expression, which promoted lipid metabolism by activating gene transcription of lipogenesis, including FASN and SC, promoting proliferation of hepatocellular cancer cells [19]. Consistent with our data, another study demonstrated that silencing of CBS or SREBPs eliminated cell migration and invasion in ovarian cancer, whereas ectopic expression of SREBPs rescues the phenotypic effect of CBS silencing by restoring cell migration and invasion [20]. While a role for SREBPs has been reported in invasion/migration, little is known of the mechanism(s) by which SREBP1 promotes invasion. 
It is reported that ROS has a dual, dose-dependent, effect on cancer development. Mild intracellular ROS can activate various cell signal pathways, promote the proliferation, migration and invasion of cancer cells [21, 22]. MMPs are endopeptidases, secreted by cancer cells, which degrade extracellular matrix proteins promoting cancer invasiveness. MT-MMPs play an important role in invasion and metastasis of colon cancer [23, 24]. In previous studies, we investigated the roles of MMPs including MMP2, MMP7, MMP8, MMP9 and MMP13 in the mice colorectal cancer model tissue, and observed that MMP7, MMP8, MMP9 are more important in colorectal cancer invasion and migration, and that MMP7 is regulated by NF-kB pathway. Previous studies have shown that ROS can up-regulate the expression of MMP-2 and MMP-9 through NF- $\mathrm{KB}$ signaling pathway [25]. In our experiments, manipulation of SREBP1 expression showed that SREBP1 over-expression was associated with invasiveness of colon cancer cells, angiogenesis of umbilical vein endothelial cells, and increased intracellular ROS level. All three of these phenotypes are associated with tumor cell invasion and metastasis. We also found that the phosphorylation of NF- $\mathrm{kB}$ p65 and the expression of MMP7 are positively correlated with the levels of SREBP1 and ROS. We therefore propose that SREBP1 promotes the invasion of colon cancer cells through the NF-kB-MMP7 axis through increased ROS. While SREBP1 can up-regulate ROS and NF- $\mathrm{KB}$, the direct causal relationship between ROS and NF- $\mathrm{kB}$ was not revealed in our article. Hao $\mathrm{Wu}$ has suggested that over-expression of HNF1b increases the expression of GPx1, decreases the expression of ROS, SREBP1, ACC and FAS, and NF-kB-mediated inflammation [26]. How SREBP1 enhances ROS content and how SREBP1 results in NF-kB p65 phosphorylation are the focus of further studies.

\section{Conclusion}

In this study, we demonstrate that SREBP1 expression could not only increase the proliferation of tumor cells by modulating the lipid metabolic pathway, it may also activate the NF- $\mathrm{KB}$ pathway, elevate the expression of MMP7 to promote tumor invasion and metastasis. SREBP1 is a pro-oncogene in invasion of colorectal cancer, and could be an important target for the treatment of colo-rectal cancers.

\section{Additional file}

Additional file 1: A. Expression of MMP8 and MMP9 is not associated with expression level of SREBP1. There were no significant difference between the expression of MMP8 and MMP9 in tumor cells that express normal-level SREBP1 after over-expressed SREBP1 in the HT29+ cell line and stably knocked down SREBP1 in the SW620 cell line. B. Detection of MMP8 and MMP9 in colorectal cancer cells with SREBP1 gene intervention. There were no difference expression of MMP8 and MMP9 between normal-level SREBP1 after over-expressed SREBP1 in the HT29 cell line.(MMP8: HT29 vs. HT29 SREBP $1^{\circ e}: 1.15 \pm 0.32$ vs. $1.04 \pm 0.25, P=0.523$; MMP9: HT29 vs. HT29 SREBP $1^{\text {oe }}: 1.06 \pm 0.34$ vs. $\left.0.94 \pm 0.29, P=0.518\right)$. There was no significant difference between SW620 and stably knocked down SREBP1 in the SW620 cell line as well. (MMP8: SW620 vs. SW620 SREBP $1^{\mathrm{kd}}, 0.97 \pm 0.12$ vs. $1.02 \pm$ $0.49, P=0.398 ;$ MMP9: SW620 vs. SW620 SREBP $1^{\mathrm{kd}}, 0.94 \pm 0.18$ vs. $0.77 \pm 0.12$, $P=0.085)$. (TIF $1276 \mathrm{~kb})$

\section{Abbreviations}

AJCC: American Joint Committee on Cancer; COPII: Coat protein complex II; CRC: Colorectal cancer; DHE: Dihydroethidium; DSS: Dextran sulfate sodium salt; HMG-CoA: 3-hydroxy-3-methylglutaryl COA; HUVEC: Human umbilical vein endothelial cells; IHC: Immunohistochemistry; ROS: Reactive oxygen species; shRNAs: Short hairpin RNAs; SREBP1: Sterol-regulatory element binding protein 1; SREBPs: Sterol-regulatory element binding proteins; TCM: Tumor cell conditioned culture supernatant

\section{Acknowledgements}

We gratefully acknowledge Dr. Robert Cardnell University of Texas MD Anderson Cancer Center for scientific and languages editing.

\section{Authors' contributions}

YG and XM conceived and designed the study; XN was responsible for analysis data and wrote the paper; XS performed data analysis; BL and $\mathrm{HZ}$ collected data and test experiment; BY and XL test experiment; $T Y$ and $Y H$ culture cell; SL interpreted data. All authors read and approved the final manuscript.

\section{Funding}

This work was supported by grants from National Natural Science Foundation of China (81401921), The funding bodies had no role in the design of the study or collection, analysis, and interpretation of the data; or writing the manuscript.

\section{Availability of data and materials}

The data supporting the conclusions of this article are included within the article (and its additional file). Additionally, the data are available to interested researchers from the corresponding author on reasonable request.

\section{Ethics approval and consent to participate}

This trial study was approved by the Ethics Committee of the Cancer Hospital of Harbin Medical University. The work related to medical ethics in this study was performed in compliance with the Helsinki Declaration and the International Ethical Guidelines for Biomedical Research Involving Human Subjects, promulgated by the International Committee of Medical Scientific Organizations. Harbin Tumor Hospital of Medical University is a teaching hospital. Each patient has signed an informed consent form for secondary use of medical history/biological specimen. All cell lines used in this study were purchased from the American Type Culture Collection. There were no cell lines that required ethics approval for their use.

\section{Consent for publication}

Not applicable

\section{Competing interests}

The authors declare that they have no competing interests.

\section{Author details}

'The Department of Radiotherapy, Beijing Luhe Hospital, Capital Medical University, Beijing, China. ${ }^{2}$ The Department of Radiotherapy, Cancer Hospital, Harbin Medical University, Harbin, China. ${ }^{3}$ Systemomics Center, College of Pharmacy, and Genomics Research Center, Harbin Medical University, Harbin, China. ${ }^{4}$ The Key Laboratory of Myocardial Ischemia, Chinese Ministry of Education, Harbin, Heilongjiang, China. 
Received: 14 December 2018 Accepted: 2 July 2019

Published online: 12 July 2019

\section{References}

1. Lin OS. Acquired risk factors for colorectal cancer. Methods Mol Biol. 2009; 472:361-72.

2. Takahashi $H$, Hosono $K$, Endo H, Nakajima A. Colon epithelial proliferation and carcinogenesis in diet-induced obesity. J Gastroenterol Hepatol. 2013; 28(Suppl 4):41-7.

3. Suchanek S, Grega T, Ngo O, Vojtechova G, Majek O, Minarikova P, Brogyuk N, Bunganic B, Seifert B, Dusek L, et al. How significant is the association between metabolic syndrome and prevalence of colorectal neoplasia? World J Gastroenterol. 2016:22(36):8103-11.

4. Hua XX, Wu J, Goldstein JL, Brown MS, Hobbs HH. Structure of the human gene encoding sterol regulatory element binding protein-1 (SREBF1) and localization of SREBF1 and SREBF2 to chromosomes 17p11.2 and 22q13. Genomics. 1995:25(3):667-73.

5. Yokoyama C, Wang XD, Briggs MR, Admon A, Wu J, Hua XX, Goldstein JL, Brown MS. SREBP-1, a basic-helix-loop-helix-leucine zipper protein that controls transcription of the low density lipoprotein receptor gene. Cell. 1993;75(1):187-97.

6. Han JB, Li EW, Chen LG, Zhang YY, Wei FC, Liu JY, Deng HT, Wang YG. The CREB coactivator CRTC2 controls hepatic lipid metabolism by regulating SREBP1. Nature. 2015;524(7564):243-6.

7. Luo XJ, Cheng C, Tan ZQ, Li NM, Tang M, Yang LF, Cao Y. Emerging roles of lipid metabolism in cancer metastasis. Mol Cancer. 2017;16(1):76.

8. Tudek B, Zdzalik-Bielecka D, Tudek A, Kosicki K, Fabisiewicz A, Speina E. Lipid peroxidation in face of DNA damage, DNA repair and other cellular processes. Free Radic Biol Med. 2017;107:77-89.

9. $\mathrm{MoH}$, Elson CE. Studies of the isoprenoid-mediated inhibition of mevalonate synthesis applied to cancer chemotherapy and chemoprevention. Exp Biol Med (Maywood). 2004;229(7):567-85.

10. Gao YY, Li X, Yang M, Zhai Q, Liu XL, Wang GY, Lu XL, Wu Q, Wu J, Yang YM, et al. Colitis-accelerated colorectal cancer and metabolic dysregulation in a mouse model. Carcinogenesis. 2013;34(8):1861-9.

11. Vazquez-Martin A, Colomer R, Brunet J, Lupu R, Menendez JA. Overexpression of fatty acid synthase gene activates HER1/HER2 tyrosine kinase receptor in human breast epithelial cells. Cell Prolif. 2008;41:59-85.

12. Lee $\mathrm{JH}$, Jeon $Y G$, Lee $\mathrm{KH}$, Lee HW, Park J, Jang $H$, Kang $M$, Lee $H S$, Cho HJ, Nam DH, et al. RNF20 suppresses tumorigenesis by inhibiting SREBP1cPTTG1 Axis in kidney Cancer. Mol Cell Biol. 2017;37:e00265-17.

13. Luo D, Xiao HW, Dong JL, Li Y, Feng GX, Cui M, Fan SJ. B7-H3 regulates lipid metabolism of lung cancer through SREBP1-mediated expression of FASN. Biochem Biophys Res Commun. 2017:482(4):1246-51.

14. Shafiee MN, Mongan N, Seedhouse C, Chapman C, Deen S, Abu J, Atiomo W. Sterol regulatory element binding protein-1 (SREBP1) gene expression is similarly increased in polycystic ovary syndrome and endometrial cancer. Acta Obstet Gynecol Scand. 2017:96(5):556-62.

15. Zhang JX, Wang XL, Vikash V, Ye Q, Wu DD, Liu YL, Dong WG. ROS and ROS-mediated cellular signaling. Oxidative Med Cell Longev. 2016:2016:1-18.

16. Ho BY, Wu YM, Chang KJ, Pan TM. Dimerumic acid inhibits SW620 cell invasion by attenuating H2O2-mediated MMP-7 expression via JNK/C-Jun and ERK/C-Fos activation in an AP-1-dependent manner. Int J Biol Sci. 2011; 7(6):869-80.

17. Hotta K, Bodkin NL, Gustafson TA, Yoshioka S, Ortmeyer HK, Hansen BC. Age-related adipose tissue mRNA expression of ADD1/SREBP1, PPARgamma, lipoprotein lipase, and GLUT4 glucose transporter in rhesus monkeys. J Gerontol A Biol Sci Med Sci. 1999:54(5):B183-8.

18. Chen J, Yue J, Liu Y, Liu J, Jiao KL, Teng MY, Hu CY, Zhen J, Wu MX, Li Z, et al. Blocking of STAT-3/SREBP1-mediated glucose-lipid metabolism is involved in dietary phytoestrogen-inhibited ovariectomized-induced body weight gain in rats. J Nutr Biochem. 2018;61:17-23.

19. Yin F, Sharen G, Yuan F, Peng Y, Chen R, Zhou X, Wei H, Li B, Jing W, Zhao J. TIP30 regulates lipid metabolism in hepatocellular carcinoma by regulating SREBP1 through the Akt/mTOR signaling pathway. Oncogenesis. 2017;6(6):e347.

20. Chakraborty PK, Xiong X, Mustafi SB, Saha S, Dhanasekaran D, Mandal NA, McMeekin S, Bhattacharya R, Mukherjee P. Role of cystathionine beta synthase in lipid metabolism in ovarian cancer. Oncotarget. 2015;6(35): 37367-84.
21. Kleinerjr D, Stetler-Stevenson WG. Structural biochemistry and activation of matrix metalloproteases. Curr Opin Cell Biol. 1993;5(5):891-7.

22. Storz P. Reactive oxygen species in tumor progression. Front Biosci. 2005;10: 1881-96.

23. Brown GT, Murray Gl. Current mechanistic insights into the roles of matrix metalloproteinases in tumour invasion and metastasis. J Pathol. 2015;237. 273-81.

24. Conlon GA, Murray Gl. Recent advances in understanding the roles of matrixmetalloproteinases in tumour invasion and metastasis. J Pathol. 2019; 247:629-40.

25. Tsai SH, Huang PH, Hsu YJ, Peng YJ, Lee CH, Wang JC, Chen JW, Lin SJ. Inhibition of hypoxia inducible factor-1alpha attenuates abdominal aortic aneurysm progression through the down-regulation of matrix metalloproteinases. Sci Rep. 2016;6:28612.

26. Wu H, Yu WH, Meng FS, Mi J, Peng J, Liu JZ, Zhang XD, Hai CX, Wang X. Polychlorinated biphenyls-153 induces metabolic dysfunction through activation of ROS/NF-kappaB signaling via downregulation of HNF1b. Redox Biol. 2017:12:300-10.

\section{Publisher's Note}

Springer Nature remains neutral with regard to jurisdictional claims in published maps and institutional affiliations.
Ready to submit your research? Choose BMC and benefit from:

- fast, convenient online submission

- thorough peer review by experienced researchers in your field

- rapid publication on acceptance

- support for research data, including large and complex data types

- gold Open Access which fosters wider collaboration and increased citations

- maximum visibility for your research: over $100 \mathrm{M}$ website views per year

At $\mathrm{BMC}$, research is always in progress.

Learn more biomedcentral.com/submissions 